\section{HOMA1-IR and HOMA2-IR indexes in identifying insulin resistance and metabolic syndrome - Brazilian Metabolic Syndrome Study (BRAMS)}

\author{
Índices HOMA1-IR e HOMA2-IR para identificação de \\ resistência à insulina e síndrome metabólica - Estudo \\ Brasileiro de Síndrome Metabólica (BRAMS)
}

Bruno Geloneze', Ana Carolina Junqueira Vasques², Christiane França Camargo

Stabe $^{2}$, José Carlos Pareja', Lina Enriqueta Frandsen Paez de Lima Rosado ${ }^{3}$,

Elaine Cristina de Queiroz ${ }^{2}$, Marcos Antonio Tambascia', BRAMS Investigators ${ }^{4}$

\begin{abstract}
Objective: To investigate cut-off values for HOMA1-IR and HOMA2-IR to identify insulin resistance (IR) and metabolic syndrome (MS), and to assess the association of the indexes with components of the MS. Methods: Nondiabetic subjects from the Brazilian Metabolic Syndrome Study were studied ( $n=1,203,18$ to 78 years). The cut-off values for IR were determined from the $90^{\text {th }}$ percentile in the healthy group $(n=297)$ and, for MS, a ROC curve was generated for the total sample. Results: In the healthy group, HOMA-IR indexes were associated with central obesity, triglycerides and total cholesterol $(\mathrm{p}<0.001)$. The cut-off values for IR were: HOMA1-IR $>2.7$ and HOMA2-IR > 1.8; and, for MS were: HOMA1-IR > 2.3 (sensitivity: 76.8\%; specificity: 66.7\%) and HOMA2-IR > 1.4 (sensitivity: 79.2\%; specificity: 61.2\%). Conclusions: The cut-off values identified for HOMA1-IR and HOMA2-IR indexes have a clinical and epidemiological application for identifying IR and MS in Westernized admixtured multi-ethnic populations. Arq Bras Endocrinol Metab. 2009;53(2):281-287.
\end{abstract}

Keywords

Homeostasis model assessment; metabolic syndrome; insulin resistance; abdominal obesity

\section{RESUMO}

Objetivo: Determinar pontos de corte para os índices HOMA1-IR e HOMA2-IR na identificação de resistência à insulina (RI) e síndrome metabólica (SM), além de investigar a associação de ambos os índices com os componentes da SM. Métodos: Foram avaliados indivíduos não diabéticos ( $n=1.203$, 18 a 78 anos) participantes do Estudo Brasileiro de Síndrome Metabólica. Os pontos de corte para RI foram determinados com base no percentil 90 do grupo saudável ( $\mathrm{n}=297$ ) e, para SM, foi construída uma curva receiver operating characteristic $(\mathrm{ROC})$ para toda a amostra. Resultados: No grupo saudável, os índices HOMA-IR associaram-se à obesidade central, aos triglicérides e ao colesterol total $(p<0,001)$. Os pontos de corte para RI foram: HOMA1-IR > 2,7 e HOMA2-IR > 1,8; e, para SM, foram: HOMA1-IR > 2,3 (sensibilidade: 76,8\%; especificidade: 66,7\%) e HOMA2-IR > 1,4 (sensibilidade: 79,2\%; especificidade: $61,2 \%$ ). Conclusões: Os pontos de corte identificados para os índices HOMA1-IR e HOMA2-IR possuem aplicação clínica e epidemiológica na identificação de RI e SM em populações miscigenadas multiétnicas ocidentalizadas. Arq Bras Endocrinol Metab. 2009;53(2):281-287.

Descritores

HOMA; síndrome metabólica; resistência à insulina; obesidade abdominal
${ }^{1}$ Laboratório de Investigação em Metabolismo e Diabetes (Limed), Instituto Nacional de Ciência e Tecnologia, Brasil ${ }^{2}$ Laboratório de Investigação em Metabolismo e Diabetes (Limed), Universidade Estadual de Campinas (Unicamp), Campinas, SP, Brasil ${ }^{3}$ Departamento de Nutrição e Saúde, Universidade Federal de Viçosa (UFV), Viçosa, MG, Brasil ${ }^{4}$ Brazilian Metabolic Syndrome Study Group (BRAMS) -

Investigators: Ada Letícia Murro, Ana Carolina Junqueira Vasques, Ana Claudia Felici, Antonio Calixto, Aurea Oliveira Silva, Bruno Geloneze, Carla Possolo Coghi,

Carla Fiori, Christiane Stabe, Daniela Schiavo, Elaine Queiroz, Enrico Maluf Repetto, Fernanda Filgueira Hirsch, Giselle Lambert, José Carlos Pareja, José Roberto MatosSouza, Marcelo Miranda de Oliveira Lima, Marcos Antonio Tambascia, Mariana Narbot Ermetice, Sylka Rodovalho Geloneze

Correspondence to: Bruno Geloneze

Limed, Gastrocentro, Universidade de Estadual de Campinas Rua Carlos Chagas, 420 13081-970 - Campinas, SP, Brasil bgeloneze@terra.com.br

Received in Feb/09/2009 Accepted in Feb/15/2009 


\section{INTRODUCTION}

$\mathrm{T}$ the metabolic syndrome (MS) is a cluster of obesity, low HDL cholesterol, hypertension, impaired fasting glucose and elevated triglycerides, among other dysmetabolic conditios, reflecting underlying insulin resistance. MS and insulin resistance are risk factors for type 2 diabetes and are associated with cardiovascular disease morbidity and mortality (1). Insulin resistance and related metabolic conditions are becoming increasingly frequent, and a substantial proportion of apparently healthy people are reported to be insulin resistant $(2,3)$.

The homeostatic model assessment (HOMA) is a validated method to measure insulin resistance from fasting glucose and insulin. The original model HOMAl-IR, first published by Mattews and cols. in 1985 (4), has been widely used, especially in epidemiological and clinical studies. Recently, the model was updated with some physiological adjustments to a computer version (HOMA2-IR) providing a more accurate index (5). Previously, our group identified the cut-off value of 2.71 for insulin resistance based on the HOMAl-IR index distribution in the Brazilian admixtured population (6). However, there is a lack of reference values for the new model. The spectrum of HOMA-IR indexes in populations is ethnic dependence, and specific cut-off values should be established to allow its use in differentiating normal from impaired insulin sensitivity (7).

Expert groups have developing a unifying definition for the MS. The International Diabetes Federation (IDF) established a simple diagnostic tool that is convenient to use in clinical practice and can be used and compared worldwide (8). The prevalence of MS in Brazilian population has been investigated (9-11). Nonetheless, no study has evaluated the optimal cut-off values for HOMA-IR indexes in identify MS in Brazilian adults.

In light of these observations, the present study aimed: to investigate the optimal cut-off values for HOMAl-IR and HOMA2-IR to identify insulin resistance and MS in Brazilian adults; to compare the ability of both indices to identify MS; and to evaluate clinical and metabolic characteristics according to HOMA-IR indexes distribution in healthy subjects and in the total studied population, including a wide body mass index (BMI) range.

\section{METHODS}

\section{Subjects}

This study was performed as part of the Brazilian Metabolic Syndrome Study (BRAMS), a population survey on metabolic disorders. The data of 2,322 subjects were examined from the central database, and 1,203 of them attended the eligible criteria for the desired analyses: adult (age $\geq 18$ years), non-diabetics, and fasting glucose ( 54.1 to $450.5 \mathrm{mg} / \mathrm{dL}$ ) and specific insulin ranges ( 2.9 to $43.8 \mathrm{mU} / \mathrm{L}$ ) in order to allow the HOMA2-IR calculations. Afterward, the healthy group $(\mathrm{n}=297)$ was defined as: $\mathrm{BMI}<30 \mathrm{~kg} / \mathrm{m}^{2}$, HDL cholesterol $\geq 40 \mathrm{mg} / \mathrm{dL}$, triglycerides $\leq 200 \mathrm{mg} / \mathrm{dL}, \mathrm{LDL}$ cholesterol < $160 \mathrm{mg} / \mathrm{dL}$, fasting plasma glucose < $100 \mathrm{mg} / \mathrm{dL}$ and normotensive status. This study was approved by the Ethics Committee of the School of Medical Sciences of Universidade Estadual de Campinas (Unicamp), and informed consent was obtained from each participant.

\section{Clinical and biochemical analysis}

The anthropometrical measures were assessed by trained observers. Weight and height were measured with the subjects wearing light clothing and without shoes on. The waist circumference was assessed at the mid point between the lowest rib and the iliac crist at the end of a normal expiration (12). The BMI was calculated and classificated according the World Health Organization (WHO) recommendation (12).

Blood pressure measurement was taken according to the recommendations of the 5th Brazilian Guidelines on Hypertension (13). The auscultatory method was employed using a suitably calibrated mercury sphygmomanometer. The volunteers were in the sitting position and at rest for ten minutes.

Blood samples were obtained after a 12 -hour overnight fast and stored in a freezer at $-30^{\circ} \mathrm{C}$. Plasma insulin was determined using a specific radioimmunoassay kit (Linco Research Inc.). Glucose was determined by the oxidase method. Total cholesterol, HDL cholesterol and tryglicerides were measured using the colorimetric enzymatic method. LDL cholesterol fraction was calculated by the Friedwald's formula (14). The HOMAl-IR index was calculated by the formula: HOMAl-IR = fasting plasma insulin $(\mu \mathrm{U} / \mathrm{ml}) \mathrm{x}$ fasting plasma glucose $(\mathrm{mmol} /$ L)/22.5 (4). The HOMA2-IR index was obtained by the program HOMA Calculator v2.2.2 (15).

\section{Definition of metabolic syndrome}

The MS was defined using the IDF criteria (8), which considers central obesity based on the waist circumference value, plus any two of the following four fac- 
tors: raised triglycerides level $(\geq 150 \mathrm{mg} / \mathrm{dL})$ or current treatment for this; reduced HDL cholesterol $(<$ $40 \mathrm{mg} / \mathrm{dL}$ in males and $<50 \mathrm{mg} / \mathrm{dL}$ in females), or current treatment for this lipid; raised blood pressure (systolic blood pressure $\geq 130$ or diastolic blood pressure $\geq 85 \mathrm{mmHg}$ ), or current treatment with an antihypertensive drug (of previously diagnosed hypertension); raised fasting plasma glucose $(\geq 100 \mathrm{mg} / \mathrm{dL})$ or previously diagnosed type 2 diabetes.

\section{Statistical analysis}

Statistical analysis was performed with the SPSS program for Windows (version 12.0). A p value $<0.05$ was considered statistically significant. The Kolmogorov-Smirnov test was applied to assess the assumption of normality for the data. Data were reported as mean \pm standard deviation (SD) or median/interquartile range, according with the normal distribution status. The lower and upper HOMA-IR indexes quartiles were compared using the Mann-Whitney test, once the HOMA-IR indexes were not normally distributed. The categories of BMI were compared by the Kruskal-Wallis test. The Dunn's post hoc test was applied for multiple comparisons. The cut-off values for insulin resistance were based on the 90th percentile in the healthy group. For MS, a receiver operating characteristic (ROC) curve was generated for the total studied population. The areas under the ROC curve (AUC) were calculated (16) to evaluate the accuracy of the HOMA-IR indexes. The greater the AUC, the greater the discriminatory power of them for MS. The optimal cut-off value was denoted by the value that had the largest sum of sensitivity and specificity (17), and, at the same time, sensitivity and specificity $\geq 60 \%$. The $\mathrm{Z}$ statistic pairwise comparison was used to compare the AUC.

\section{RESULTS}

A total of 1,203 subjects aged 18 to 78 years participated in this study. The main characteristics of the study population are presented in Table 1 . It is observed a balanced distribution of gender; a comprehensive range of BMI, concerning eutrophic and obese subjects; and a different distribuition for the HOMA-IR indexes, that is, the HOMA2-IR presented lower values compared with the first published index. Table 2 shows the healthy group caracterization. All of them did not have any clinical and metabolic characteristics of MS. They were normotensive, normolipidemic, non obese and normal glucose tolerants.

In Figure 1, it is possible to compare the distribution of anthropometric and metabolic variables according the HOMA-IR indexes quartiles in the healthy group. The values for waist circumference, BMI, total cholesterol and triglycerides increased in the upper quartiles for both HOMA-IR indexes $(\mathrm{p}<0.05)$. LDL

\begin{tabular}{lc}
\hline Table 1. Clinical and metabolic characteristics of the total studied population \\
\hline Characteristic & $\begin{array}{c}\text { Median (interquartile range) } \\
\text { ( } \mathbf{n}=\mathbf{1 2 0 3})\end{array}$ \\
\hline Male, $\mathrm{n}(\%)$ & $511(42.5)$ \\
Female, $\mathrm{n}(\%)$ & $692(57.5)$ \\
Age, years & $41(32$ to 50$)$ \\
BMl, kg/m² & $29.6(24.9$ to 36.4$)$ \\
Systolic blood pressure, mmHg & $120(110$ to 130$)$ \\
Diastolic blood pressure, $\mathrm{mmHg}$ & $80(70$ to 90$)$ \\
Triglyceride, mg/dL & $108.5(78.0$ to 155.5$)$ \\
Total cholesterol, mg/dL & $192.0(166.0$ to 224.0$)$ \\
HDL cholesterol, mg/dL & $46.0(39.0$ to 55.0$)$ \\
LDL cholesterol, $\mathrm{mg} / \mathrm{dL}$ & $118.0(95.7$ to 145.0$)$ \\
Fasting plasma glucose, mg/dL & $88.0(81.0$ to 96.0$)$ \\
Fasting plasma insulin, mU/L & $10.1(6.1$ to 18.0$)$ \\
HOMA1-IR & $2.2(1.2$ to 4.1$)$ \\
HOMA2- IR & $1.5(0.9$ to 2.6$)$ \\
\hline
\end{tabular}

$\mathrm{BMI}=$ body mass index.

Table 2. Clinical and metabolic characteristics of the healthy group

\begin{tabular}{lc}
\hline Characteristic & $\begin{array}{c}\text { Mean } \pm \text { SD or median } \\
\text { (interquartile range) } \\
\text { ( } \mathbf{n}=\mathbf{2 9 7})\end{array}$ \\
\hline Male, $\mathrm{n}(\%)$ & $130(43.8)$ \\
Female, $\mathrm{n}(\%)$ & $167(56.2)$ \\
Age, years & $36.0(27.0$ to 46.0$)$ \\
BMI, kg/m² & $23.9 \pm 2.9$ \\
Systolic blood pressure, mmHg & $120(110$ to 120$)$ \\
Diastolic blood pressure, mmHg & $80(70$ to 80$)$ \\
Triglyceride, mg/dL & $78.0(59.5$ to 104.5$)$ \\
Total cholesterol, mg/dL & $177.1 \pm 30.9$ \\
HDL cholesterol, mg/dL & $52.0(47.0-62.0)$ \\
LDL cholesterol, mg/dL & $104.2 \pm 26.7$ \\
Fasting plasma glucose, mg/dL & $82.7 \pm 7.5$ \\
Fasting plasma insulin, $\mathrm{mU} / \mathrm{L}$ & $5.9(4.6$ to 8.9$)$ \\
HOMA1-IR & $1.23(0.92$ to 1.93$)$ \\
HOMA2- IR & $0.87(0.66$ to 1.30$)$ \\
\hline
\end{tabular}

$\mathrm{BMI}=$ body mass index; mean and SD (standard deviation) used for variables with normal distribution. 
cholesterol values were higher in the fourth quartile only for HOMAl-IR distribuition, and HDL cholesterol presented no statistically significant difference between quartiles.

The comparison of HOMA-IR indexes distribution accross the BMI categories in the total studied population is presented in Figure 2. The multiple comparisons showed a parallel increasing in HOMA-IR indexes with a rising in BMI categories $(\mathrm{p}<0.001)$, with an exception for the highest degress of obesity (obesity grade I/ II versus grade III). The distribuition of HOMA-IR indexes according to MS diagnostic is presented in Figure
3. Subjects with a positive diagnostic for MS presented higher HOMA-IR indexes values $(\mathrm{p}<0.001)$.

ROC analyse is presented in Figure 4. The AUC for the two HOMA-IR indexes were statisticaly significant $(\mathrm{p}<0.001)$. HOMAl-IR index presented the largest AUC, if compared with HOMA2-IR. Both values were slightly different $(\mathrm{p}<0.001)$, with overlapping $95 \%$ confidence intervals. Table 3 shows the optimal cut-off values identified for insulin resistance, considering the healthy subjects whose HOMAl-IR values were above the 90th percentile, and for MS, taking into account the optimal cut-off values in the ROC curve.
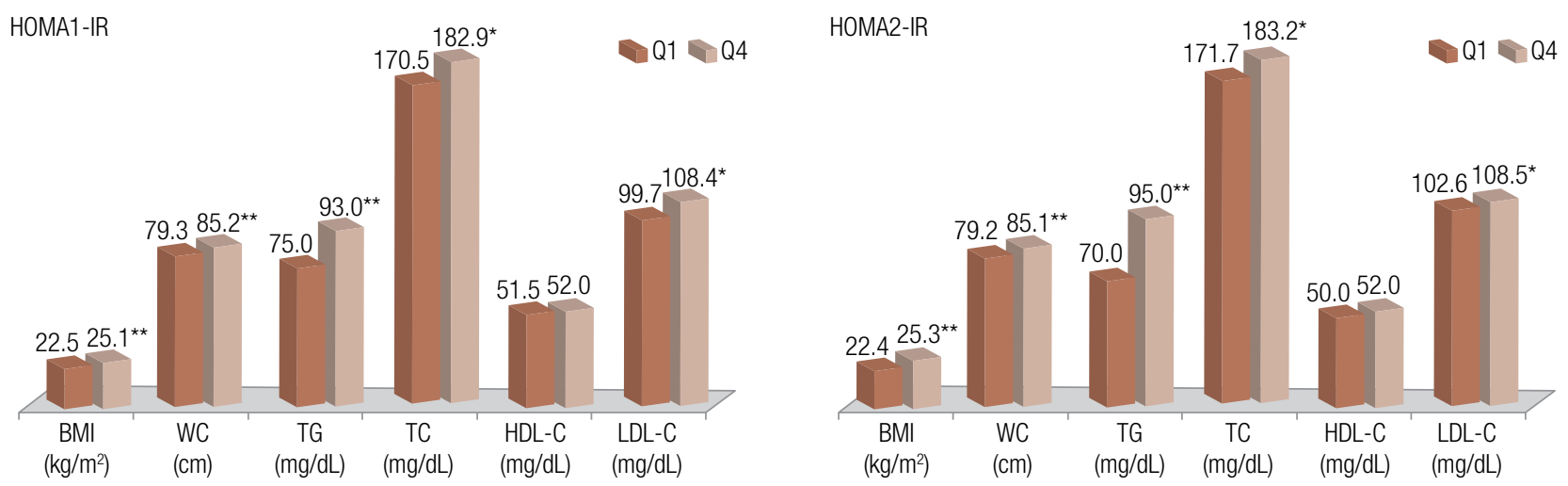

Q1 = first quartile; $\mathrm{Q} 4$ = fourth quartile; $\mathrm{BMl}=$ body mass index; $\mathrm{WC}=$ waist circumference; $\mathrm{TG}=$ triglyceride; $\mathrm{TC}=$ total cholesterol; $\mathrm{HDL}-\mathrm{C}=\mathrm{HDL}-\mathrm{cholestero} ; \mathrm{LDL}-\mathrm{C}=\mathrm{LDL}-\mathrm{cholesterol;} \mathrm{t}$-test for $\mathrm{BMI}, \mathrm{WC}$, TC and LDL-C (presented as mean) and Mann-Whitney test for TG and HDL-C (presented as median); ${ }^{*} p<0.05 ;{ }^{* \star} p<0.001$.

Figure 1. Comparison of clinical and metabolic characteristics according to HOMA-IR indexes quartiles in the healthy group.
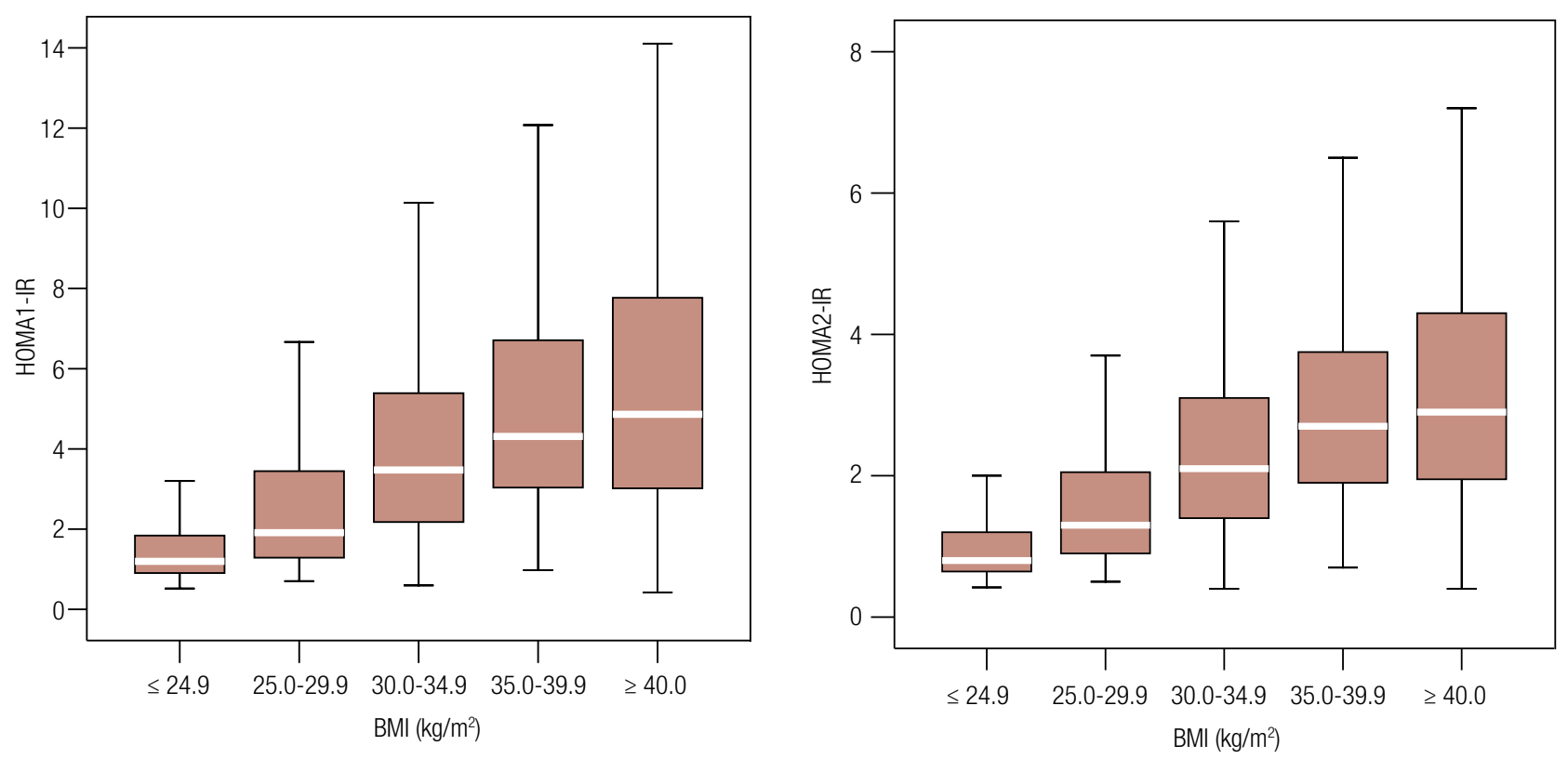

$\mathrm{BMl}=$ body mass index.

Kruskal-Wallis test. $p<0.001$.

Figure 2. Box plot comparison of HOMA-IR indexes distribution accross the BMI categories in the total studied population. 

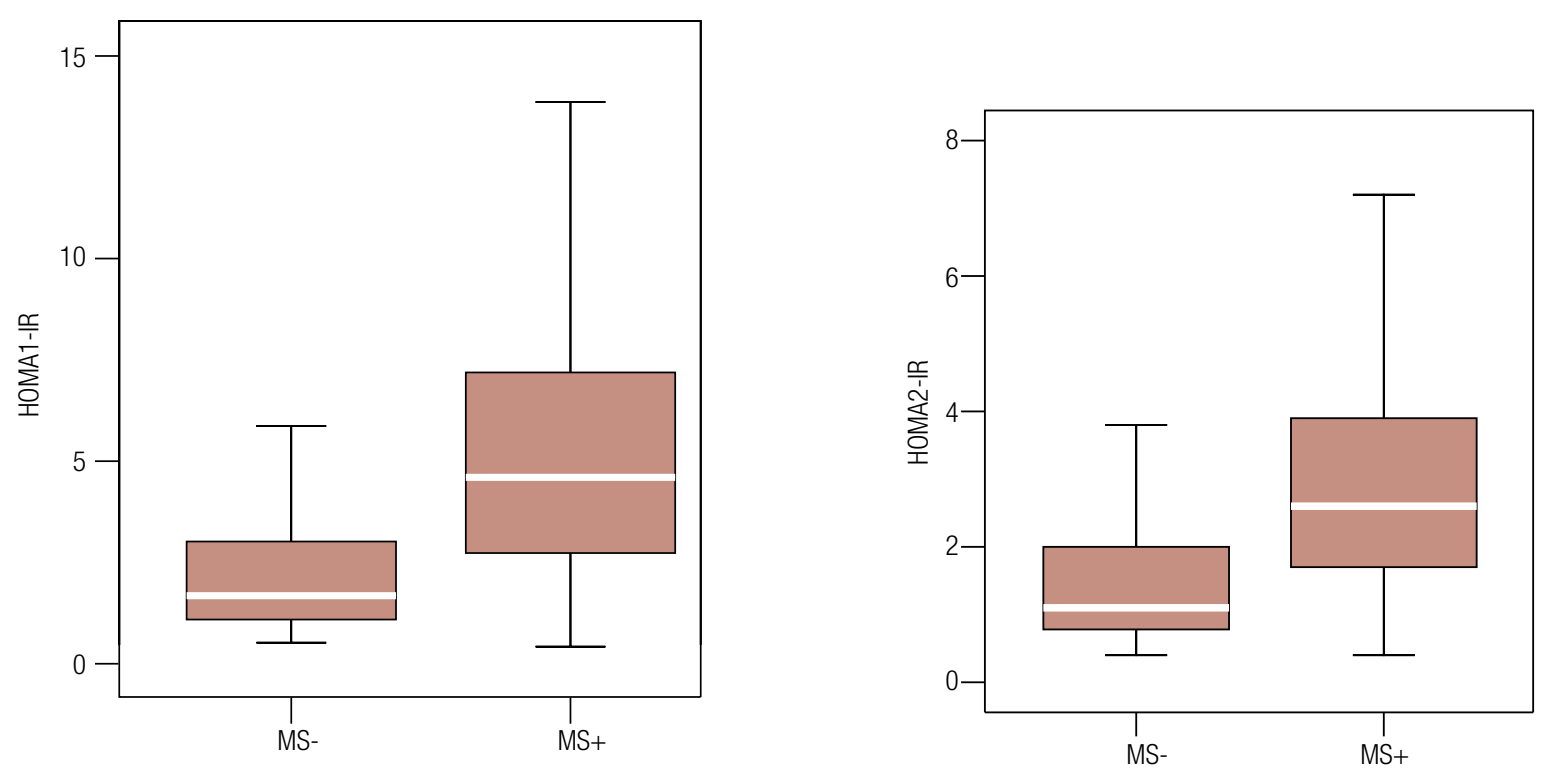

MS- = subjects without metabolic syndrome; MS+ = subjects with metabolic syndrome; Mann-Whitney test; $p<0.001$.

Figure 3. Box plot comparison of HOMA-IR indexes distribution according to metabolic syndrome diagnostic in the total studied population.

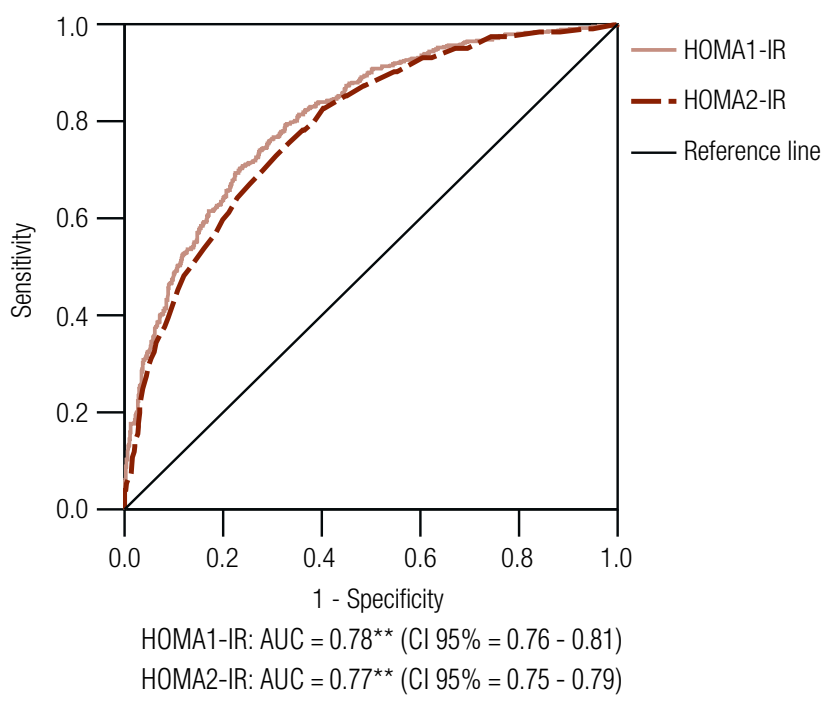

$\mathrm{AUC}=$ area under the curve; $\mathrm{Cl}=$ confidence interval; ${ }^{\star \star} \mathrm{p}<0.001$ for null hypothesis: true area $=0.5 ;$ Z statistic for pairwise comparison of AUC: HOMA1-IR $>$ HOMA2-IR; $p<0.001$

Figure 4. Receiver operating characteristic (ROC) curves comparing HOMA-IR indexes as discriminators of metabolic syndrome in the total studied population.

\section{DISCUSSION}

The present study investigated the optimal cut-off values for HOMAl-IR and HOMA2-IR to identify insulin resistance and $\mathrm{MS}$ in an admixtured population. It was also demonstrated that insulin resistance, assessed by both HOMA-IR indexes, is associated with an elevated BMI, with a worse lipoprotein profile and with a positive diagnostic for MS. Furthermore, it was verified that in the apparently healthy subjects, HOMA-IR indexes were positively associated with BMI and abdominal obesity, and with triglycerides and total cholesterol.

HOMAl-IR, the first described model, is a validated method to evaluate insulin resistance. However, according to Levy and cols. (5), the original equation is now superseded by the new model. The HOMA2-IR is a more accurate representation of the metabolic process because it models the feedback relationship between insulin and glucose in the various organs in the body (7).

\begin{tabular}{|c|c|c|c|c|}
\hline \multirow{2}{*}{ Index } & \multirow{2}{*}{$\begin{array}{c}\text { Insulin resistance } \\
\text { Cut-off value* }\end{array}$} & \multicolumn{3}{|c|}{ Metabolic syndrome } \\
\hline & & Cut-off value ** & Sensibility $(95 \% \mathrm{Cl})$ & Specificity $(95 \% \mathrm{Cl})$ \\
\hline HOMA1-IR & 2.7 & 2.3 & $76.8(72.1-80.5)$ & $66.7(63.3-70.0)$ \\
\hline HOMA2-IR & 1.8 & 1.4 & $79.2(74.7-82.8)$ & $61.2(57.6-64.6)$ \\
\hline
\end{tabular}

$\mathrm{Cl}=$ confidence interval; * the 90th percentile in the healthy group; ** the optimal cut-off value verified in ROC analysis. 
On the other hand, the HOMA2-IR has the inconvenience that only a specific range of values are acceptable for calculation. In clinical practice, this limitation makes difficult the management of insulin results outside the limits and the need for a computer to run the program. In this study, the HOMAl-IR showed an AUC statistically higher than the area verified for the new model, but without major clinical relevance, because the values of the areas were quite similar ( 0.77 and 0.78$)$ with an overlapping confidence intervals.

Most of the published cut-off points for the HOMA-IR indexes are based on measures of dispersion. In the past, our group identified the cut-off value of 2.71 for insulin resistance evaluated by the HOMAl-IR in an admixture population (6). In this study, with an updated database and a larger sample, the value of 2.7 found was equivalent, reinforcing the concept that it is a useful reference for the Brazilian adult population. The cut-off value of 2.7 shows a hight similarity to early reports. Evaluating subjects apparently healthy, Buccini and Wolfthal (18) identified the cut-off value of 2.64 in Argentinians; Bonora and cols. (19) found the value of 2.77 in Italians and Yeni-Komshian and cols. (20) verified the value of 2.7 in North Americans. In contrast, Ascaso and cols. (21) found the cut-off value of 3.8 in Spanish population.

For MS, the optimal cut-off value of 2.3 identified in the present study was smaller than the value for insulin resistance, probably because the MS involves the diagnostic of multiple disorders simultaneously, not only the insulin resistance itself, but also main underlying pathophysiological condition, the central adiposity. In Korean non-diabetic adults Lee and cols. (22) identified a very similar value of 2.34 . Recentely, the cut-off value of 2.5 was established for assessing $\mathrm{MS}$ in a cohort of Brazilian children (23).

Hence, for HOMA2-IR, there are no stabilished reference values for both, insulin resistance and MS, in the literature. We identified the cut-off value of 1.8 to detect insulin resistance, and of 1.4 for MS. The study of Buccini and Wolfthal (18) suggested the value of 1.67 to detect insulin resistance.

Obese individuals tend to be insulin resistant (24), what was demonstrated with the increasing HOMAIR indexes gradient across the growing categories of BMI. On the other hand, some associations between HOMA-IR indexes and components of MS were identified in the nonobese healthy group. In this group, the presence of higher values of BMI, triglycerides, total cholesterol and LDL cholesterol in the upper HOMAIR indexes quartiles could be explained by the body fat distribution, since the waist circumference was also increased in the upper HOMA-IR indexes quartiles. Waist circumference is a surrogate marker of abdominal fat mass. It correlates with subcutaneous and visceral fat mass and is related to increased cardiometabolic risk $(25,26)$.

In conclusion, the cut-off values identified in both models, HOMAl-IR and HOMA2-IR, for insulin resistance and MS, have a clinical and epidemiological application for Westernized admixtured multi-ethnic populations. Given the association between insulin resistance, obesity and classical components of MS in the total population and in apparently healthy individuals, the early detection of insulin resistance and MS using a simple tool like HOMA models is attractive. Effective interventions for improving insulin sensitivity and reducing abdominal obesity primarely by weight reduction and physical activity may help in preventing type 2 diabetes and cardiovascular disease.

Disclosure: No potential conflict of interest relevant to this article was reported.

\section{REFERENCES}

1. Wilson PW, D'Agostino RB, Parise H, Sullivan L, Meigs JB. Met Syn as a precursor of cardiovascular disease and type 2 diabetes mellitus. Circulation. 2005;112(20):3066-72.

2. Ezenwakan $\mathrm{CE}$, Kalloo R. Indices of obesity, dyslipidemia, and insulin resistance in apparently healthy Caribbean subjects. J Clin Lab Anal. 2003;17(1):6-11.

3. Conus $F$, Allison DB, Rabasa-Lhoret R, St-Onge M, St-Pierre DH, Tremblay-Lebeau A, et al. Metabolic and behavioral characteristics of metabolically obese but normal-weight women. J Clin Endocrinol Metab. 2004;89(10):5013-20.

4. Matthews DR, Hosker JP, Rudenski AS, Naylor BA, Treacher DF, Turner RC. Homeostasis model assessment: insulin resistance and beta-cell function from fasting plasma glucose and insulin concentrations in man. Diabetologia. 1985;28(7):412-9.

5. Levy JC, Matthews DR, Hermans MP. Correct homeostasis model assessment (HOMA) evaluation uses the computer program. Diabetes Care. 1998;21(12):2191-2.

6. Geloneze B, Repetto EM, Geloneze SR, Tambascia MA, Ermetice MN. The threshold value for insulin resistance (HOMA-IR) in an admixtured population IR in the Brazilian Metabolic Syndrome Study. Diabetes Res Clin Prac. 2006;72(2):219-20.

7. Wallace TM, Levy JC, Matthews DR. Use and abuse of HOMA modeling. Diabetes Care. 2004;27(6):1487-95.

8. Alberti KG, Zimmet $P$, Shaw J. Metabolic syndrome - a new world-wide definition. A Consensus Statement from the International Diabetes Federation. Diabet Med. 2006;23(5):469-80.

9. Oliveira EP, Souza MLA, Lima MDA. Prevalência de síndrome metabólica em uma área rural do semi-árido baiano. Arq Bras Endocrinol Metab. 2006;50(3):456-65. 
10. Salaroli LB, Barbosa GC, Mill JG, Molina MCB. Prevalência de síndrome metabólica em estudo de base populacional, Vitória, ES, Brasil. Arq Bras Endocrinol Metab. 2007;51(7):1143-52.

11. Velásquez-Meléndez G, Gazzinelli A, Côrrea-Oliveira R, Pimenta AM, Kac G. Prevalence of metabolic syndrome in a rural area of Brazil. Sao Paulo Med J. 2007;125(3):155-62.

12. World Health Organization. Obesity: preventing and managing the global epidemic. Report of a WHO Consultation. Geneva: World Health Organization, 2000.

13. Sociedade Brasileira de Cardiologia; Sociedade Brasileira de Hipertensão; Sociedade Brasileira de Nefrolo. V Diretrizes Brasileiras de Hipertensão Arterial. Arq Bras Cardiol. 2007;89(3):24-79.

14. Friedwald WT, Levy RI, Fredrickson DS. Estimation of the concentration of low-density lipoprotein cholesterol in plasma, without use of the preparative ultracentrifuge. Clin Chem. 1972;18(6):499-502.

15. The Oxford Centre for Diabetes. Endocrinology \& Metabolism. Diabetes Trial Unit. HOMA Calculator. Available from: http://www. dtu.ox.ac.uk/ Acessed March 2009.

16. Hanley JA, McNeil BJ. A method of comparing the areas under receiver operating characteristic curves derived from the same cases. Radiology. 1983;148(3):839-43.

17. Van der SchouwYT, Verbeek AL, Ruijs JH. ROC curves for the initial assessment of new diagnostic tests. Fam Pract. 1992;9(4):506-11.

18. Buccini GS, Wolfthal DL. Valores de corte para índices de insulinorresistencia, insulinosensibilidad e insulinosecreción derivados de la fórmula HOMA y del programa HOMA2. Interpretación de los datos. Rev Argent Endocrinol Metab. 2008;45(1):3-21.

19. Bonora E, Kiechl S, Willeit J, Oberhollenzer F, Egger G, Targher G, et al. Prevalence of insulin resistance in metabolic disorders: the Bruneck Study Diabetes. 1998;47(10):1643-9.
20. Yeni-Komshian H, Carantoni M, Abbasi F, Reaven GM. Relationship between several surrogate estimates of insulin resistance and quantification of insulin-mediated glucose disposal in 490 healthy nondiabetic volunteers. Diabetes Care. 2000;23(2):171-5.

21. Ascaso JF, Romero P, Real JT, Priego A, Valdecabres C, Carmena R. Cuantificación de insulinoresistencia con los valores de insulina basal e índice HOMA en una población no diabética. Med Clin. 2001;117(x):530-3.

22. Lee S, Choi S, Kim HJ, Chung YS, Lee KW, Lee HC, et al. Cutoff values of surrogate measures of insulin resistance for metabolic syndrome in Korean non-diabetic adults. J Korean Med Sci. 2006;21(4):695-700.

23. Madeira IR, Carvalho CNM, Gazolla FM, Matos HJ, Borges MA, Bordallo MAN. Ponto de corte do Índice Homeostatic Model Assessment for Insulin Resistance (HOMA-IR) avaliado pela curva Receiver Operating Characteristic (ROC) na detecção de síndrome metabólica em crianças pré-púberes com excesso de peso. Arq Bras Endocrinol Metab. 2008;52(9):1466-73.

24. Reaven GM. Insulin resistance: the link between obesity and cardiovascular disease. Endocrinol Metab Clin North Am. 2008;37(3):581-601.

25. McLaughlin T, Allison G, Abbasi F, Lamendola C, Reaven G. Prevalence of insulin resistance and associated cardiovascular disease risk factors among normal weight, overweight, and obese individuals. Metabolism. 2004;53(4):495-9.

26. Pouliot MC, Després JP, Lemieux S, Moorjani S, Bouchard C, Tremblay A. Waist circumference and abdominal sagittal diameter: best simple anthropometric indexes of abdominal visceral adipose tissue accumulation and related cardiovascular risk in men and women. Am J Cardiol.1994;73(7):460-8. 